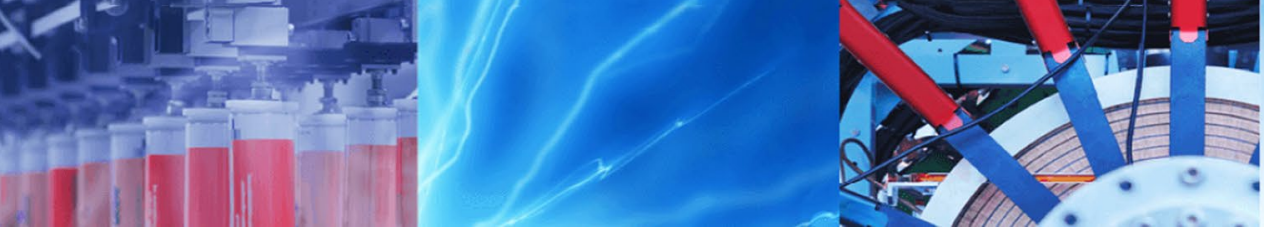

Research Article

\title{
Analysis of the extension behavior of reflective cracks in asphalt pavements based on dry shrinkage property
}

\author{
Min Min Xiao ${ }^{1} \cdot \operatorname{Lin}^{F_{a n}}{ }^{1}(1)$ \\ Received: 11 September 2021 / Accepted: 3 February 2022 \\ Published online: 02 March 2022 \\ (c) The Author(s) 2022 OPEN
}

\begin{abstract}
In order to study the extension behavior of dry shrinkage type reflective cracks in asphalt pavements, this paper uses the differential equation theory to derive the calculation formula for the inhomogeneous gradient distribution of dry shrinkage stress in the subgrade. Meanwhile, based on the traction separation rule and damage behavior equation, the extended finite element method is applied to simulate the extension path and tip stress response of dry shrinkage type reflection crack, and then analyze the influence of Semi-rigid subgrade structure and material parameters on the extension behavior of dry shrinkage type cracks. The results show that the dry shrinkage stress of Semi-rigid type base is related to the elastic modulus of base course material, dry shrinkage coefficient, uniform variation of moisture content, horizontal deformation resistance coefficient, and structural dimensions of Semi-rigid type base. Micro cracks in the Semi-rigid type base under the action of dry shrinkage stress will occur two-way extension behavior, one is to continue cracking below the base course, and the other one is the reflection extension into into the surface layer, in addition, the extension speed of the reflected cracks in the surface layer is much larger than the crack cracking speed in the base course. Reducing the modulus of the base course, increasing the thickness of the base course and controlling the variation of the moisture content of the base course within the limit value can effectively retard the emergence and extension rate of reflection cracks.
\end{abstract}

Keywords Road engineering · Reflective cracking · Dry shrinkage stress · Extensional behavior · Extended finite element

\section{Introduction}

Semi-rigid type base asphalt pavement is a non-homogeneous viscoplastic material formed by mixing asphalt, coarse and fine aggregates, water and admixtures. At present, more than $90 \%$ of China's high-grade highway asphalt pavement base and sub-base using Semi-rigid type base materials, and Semi-rigid type base asphalt pavement has become the main structure type of China's high-grade highway asphalt pavement. With the rapid development of road construction, the problem of Semi-rigid type base asphalt pavement cracking has also attracted more and more attention. Due to the initial defects such as microporosity, air pockets and coarse and fine aggregate separated in the Semi-rigid type base, there must exist micro-cracks in the base. Under the action of multiple coupling factors such as temperature shrinkage stress, dry shrinkage stress, and traffic load, stress concentration occurs at the crack tip, resulting in the extension of the base micro-crack to the surface layer and rapidly penetrating the whole surface layer, which directly affects the capacity and service life of asphalt pavement. Therefore, it is significant to investigate the extension behavior of dry

Lin Fan, 15161105613@163.com | ${ }^{1}$ College of Urban Construction and Safety Engineering, Shanghai Institute of Technology, Shanghai 201418 , China.

SN Applied Sciences ～～～～（2022) 4:88 $\quad$ https://doi.org/10.1007/s42452-022-04974-5 
shrinkage type reflection cracks in Semi-rigid type base asphalt pavements.

\subsection{Asphalt pavement reflection cracks}

A number of studies have been conducted to investigate the mechanism of pavement reflection cracking and strategies to mitigate pavement reflection cracking. Many researchers have studied pavement cracking through laboratory tests. Ruiz-Riancho et al [1] evaluated the capability of the encapsulated asphalt rejuvenators to mitigate reflective cracking by reproducing trafficinduced reflective cracking in gypsum asphalt mixtures. The research results effectively reduce pavement reflection cracking and enhance pavement fatigue durability. Das et al [2] experimentally evaluated a new ductile concrete interlayer made of engineered cementitious composite (ECC), and the ECC interlayer was effective in inhibiting or delaying reflection cracking in composite pavements. Fang et al [3] proposed a new construction method of continuous construction of base and asphalt layers (CCBA), which can effectively reduce reflection cracks in asphalt pavements. The above studies propose targeted strategies to delay reflective cracking of pavements, however, they do not reveal the mechanism of reflective cracking of pavements in depth. Oshone et al [4] experimentally investigated the dependence of overlay field cracking performance on overlay thickness and fracture energy of asphalt mixture, calculated different cracking performance measures such as average transverse cracking rate (ATCR), maximum transverse cracking rate (MTCR) and transverse cracking performance index (TCTotal), and proposed new performance parameters for reflective cracking performance assessment. Richard Ji et al [5] studied the laboratory characteristics of temperature-induced reflection cracks using a laboratory test suite from Custom Texas OT. Pirmohammad and Ayatollahi [6] investigated the low temperature cracking resistance of asphalt pavements under different loading modes through indoor tests. The results revealed that shear loading is an essential cause of the variation in the low temperature flexural strength of asphalt pavements. Gonzalez-Torre et al [7] tested the effect of different loading frequencies on the expansion of reflective cracks in pavements and showed that low frequency loading has a greater effect on the expansion of reflective cracks. Ji [8] concluded from multivariate indoor experiments that the main factors causing reflection cracks in pavements are base temperature shrinkage stress and traffic loading. These studies revealed the mechanism of reflective cracking of pavements under certain characteristics, such as: cyclic temperature characteristics, multi-frequency loading characteristics, however, they ignore that the dry shrinkage of the base material is also an significant cause of reflective cracking of pavements. Due to the restrictive indoor experimental conditions, the results of the study do not accurately simulate the reflection cracking of real pavements. Compared with the ambiguity of the indoor experimental results, the extended finite element is an effective method to investigate the expansion of pavement cracks along arbitrary paths. Researchers Dedicated to investigate reflection cracking of asphalt pavements by extended finite element method. Wang and Zhong [9] adopted extended finite elements to describe the reflection cracking mechanism of asphalt pavements under combined temperature and traffic flow loads, and investigated the stress distribution, crack initiation temperature, crack opening displacement and crack propagation path of asphalt pavements. The results of this study have advanced the research process of pavement reflection cracking mechanism. Wang et al [10] applied the temperature distribution to the XFEM model to research the mechanism of cyclic temperature on the reflective cracking of asphalt pavement, and the results showed that the crack opening path, crack width and stress distribution were influenced by the initial crack opening length and initial inclination of the cracks. This research is expected to provide more scientific insight to advance current structural pavement design practices and pavement rehabilitation. Dave et al [11] studied the fracture mechanism of asphalt pavement surface layers caused by cyclic temperature and traffic loads. Kim and Buttlar [12] studied the extension behavior of reflective cracks in pavements under the combined effect of temperature and traffic loads. Lancaster et al [13] numerically simulated the crack extension behavior by finite element. Myers et al [14] considered that the extension direction of reflection cracks is related to the crack length by fracture mechanics theory and finite element method. Huang et al [15] studied the fatigue expansion of temperature-shrinkage reflective cracks by a modified Paris formula, and concluded that increasing the ultimate fracture energy release rate of asphalt mixtures could extend their fatigue life, which promoted the investigation of the mechanism of temperature-shrinkage reflective crack expansion in pavements. However, the above-mentioned studies also focused on reflective cracking of pavements under temperature and load, and still ignored the effect of base dry shrinkage on reflective cracking of pavements. In summary, the current research on the reflection cracking mechanism of asphalt pavement is focused on temperature shrinkage type reflection cracking and traffic load type reflection cracking, but the research on the reflection cracking 
mechanism of pavement caused by the dry shrinkage effect of Semi-rigid type base is scarce.

\subsection{Semi-rigid type base dry shrinkage effect}

Most studies on the drying shrinkage of construction materials have focused on the drying shrinkage of cement materials. Tran et al [16] proposed that introducing internal restraints using fibres or aggregate could effectively retard the drying shrinkage of cementitious materials. This research provides an effective method to mitigate the drying shrinkage of materials. Qomi et al [17] revealed the nature of dry shrinkage of cement materials from the nano-scale through atomic modeling, and this study promoted the study of the dry shrinkage mechanism of cement materials. Song et al [18] recorded the drying shrinkage and drying creep of concrete mixes, and the results revealed the basic mechanical properties of drying shrinkage of concrete materials. Cuesta et al[19] analyzed the effect of recycled polymers (RA) on the mechanical properties of high performance concrete. The results show that the maturity of RA affects the mechanical properties of high-strength concrete and can effectively reduce the drying shrinkage of high-strength concrete. Meanwhile, a series of studies have been conducted on the dry shrinkage behavior of asphalt composites. Tong et al [20] studied the hydration and dry shrinkage behavior of cement-emulsified asphalt composites (CEAC) through an in-depth learning framework, which revealed to some extent the characteristics of the drying shrinkage behavior of asphalt composites. Li et al [21] conducted drying shrinkage and temperature shrinkage tests, and the results showed that using scrap steel slag instead of base steel slag as a base material can effectively reduce the drying shrinkage deformation of Semi-rigid type base materials. The above studies are mainly concerned with the drying shrinkage of cement materials. However, as Semi-rigid type base asphalt pavement is a non-homogeneous and complex material, some mechanisms of drying shrinkage of cement materials are not generally applicable to the analysis of drying shrinkage of pavement base. Although Tong and Li's study provides a scientific description of the drying shrinkage behavior of asphalt composites, the research results focus on strategies to mitigate the drying shrinkage of the base material without an in-depth study of the drying shrinkage mechanism of the Semi-rigid type base material. In summary, the current research has not yet revealed the regularity of dry shrinkage deformation caused by the difference of moisture inside and outside the substrate material. The calculation formula and the principal structure model of drying shrinkage stress of Semi-rigid type base material still exist gaps.
In this paper, we first analyze the uncoordinated dry shrinkage deformation caused by the difference of humidity inside and outside the base layer, construct a Semi-rigid type base layer dry shrinkage stress model and utilize the theory of multi-order differential equations to recur the base layer dry shrinkage stress calculation formula. Secondly, based on the traction separation rule and damage behavior equation, the extension path and crack tip stress response of dry shrinkage reflective cracks in asphalt pavement are simulated by using extented finite element method (XFEM). Meanwhile, the dry shrinkage cracking mechanism of Semi-rigid type base asphalt pavement is analyzed. Finally, by changing the structural and material parameters of the Semi-rigid type base, the parameters of the modulus of elasticity of the base, the thickness of the base, the amount of water content variation and the dry shrinkage coefficient are selected to investigate the influence of the relevant parameters on the reflective cracking behavior of the pavement, and to provide scientific guidance for the design and maintenance of Semi-rigid type base asphalt pavements.

\section{Models and theories}

\subsection{Semi-rigid type base dry shrinkage stress calculation model}

In actual engineering, as the moisture in the asphalt pavement base material diffuses into the surrounding dry air, an uneven moisture diffusion field and free dry shrinkage strain is generated in the base structure. Under the effect of internal and external humidity gradient, the uncoordinated dry shrinkage deformation caused by the difference between internal and external humidity of the base layer generates dry shrinkage stress field [22], thus causing the internal cracking of the base layer and expanding to the surface layer to form reflective penetration cracks. Therefore, the following assumptions were made in establishing the model for the calculation of dry shrinkage stresses in Semi-rigid type base [23]:

(1) The moisture distribution of the Semi-rigid type base material is approximately uniformly distributed, and the resulting shrinkage deformation is also uniformly shrinkage.

(2) The presence of mutual friction between the base layer and the lower subgrade produces the frictional resistance in the horizontal direction.

(3) Semi-rigid type base layer in the dry shrinkage effect that the whole section of the base is in a uniform state of stress. At the same time, because of the maximum value of dry shrinkage stress in the middle of the base, 
the stress value at the end of the base layer is smaller, so it can be approximated that the dry shrinkage stress of the base only has numerical fluctuations along the tangential direction of the pavement, and is uniformly distributed in the normal direction.

The resulting uniform force model of asphalt pavement with height, width and length is shown in Fig. 1.

\subsection{Asphalt pavement simulation model}

\subsubsection{Extended finite element method (XFEM) theoretical basis}

The extended finite element method is a numerical analysis method to deal with discontinuous problem. The method overcomes the dependence on computational network partitioning in traditional finite element calculation of fracture problems, it can greatly improve computational efficiency by eliminating the necessity of mesh reconstruction when simulating crack extension problems [24]. Meanwhile, the method adopts a special displacement function, which allows the existence of the discontinuity property by extending the degrees of freedom, and can simulate the arbitrariness, solve the initial position of the relevant path crack and the crack extension process [25].

Therefore, during the study of the dry shrinkage type reflective crack extension behavior of asphalt pavements, the numerical simulation of crack extension behavior was performed based on the XFEM module in ABAQUS. The XFEM modeling of the reflection crack extension behavior of asphalt pavement is roughly divided into the following parts [26].

(1) Finite element meshing of the material with neglecting the internal details of the structure.
(2) Numerical simulation of cracks in the cracking cell in the traction-displacement model using the maximum principal stress criterion as the cracking criterion and the damage initial criterion and the damage evolution law.

(3) Adding additional functions related to the inner boundary in the unit shape function. The discontinuity generated by crack expansion is realized by defining additional degrees of freedom.

The crack extension displacement vector(u) can be expressed as:

$u=\sum_{l=1}^{N} N_{l}(x)\left[u_{1}+H(x) a_{l}+\sum_{a=1}^{4} F_{a}(x) b_{l}^{a}\right]$

where $N_{l}(x)=$ The displacement shape function of any node $x$ in the domain; $u_{l}=$ Displacement vector at the node $x ; a_{l}=$ Enrichment node free vector; $H(x)=$ Discontinuous jump function along the fracture surface; $b_{1}^{\alpha}=$ Enrichment node free vector; $F_{a}(x)=$ Crack tip stress asymptotic function.

For asphalt mixture, under the action of the tip stress gradient field, continuous damage cracking occurs in the region near the crack tip, resulting in the disappearance of the asphalt mixture tip stress singularity and crack extension is a natural process [27], so the third term in the displacement vector of the above equation does not exist in this analysis of asphalt pavement reflection crack extension behavior.

\subsubsection{Fracture criteria}

A damage model is required in the simulation of crack extension. The damage mechanism of the model includes two criteria: damage initiation criterion and damage evolution criterion.
Fig. 1 Semi-rigid type base dry shrinkage stress model
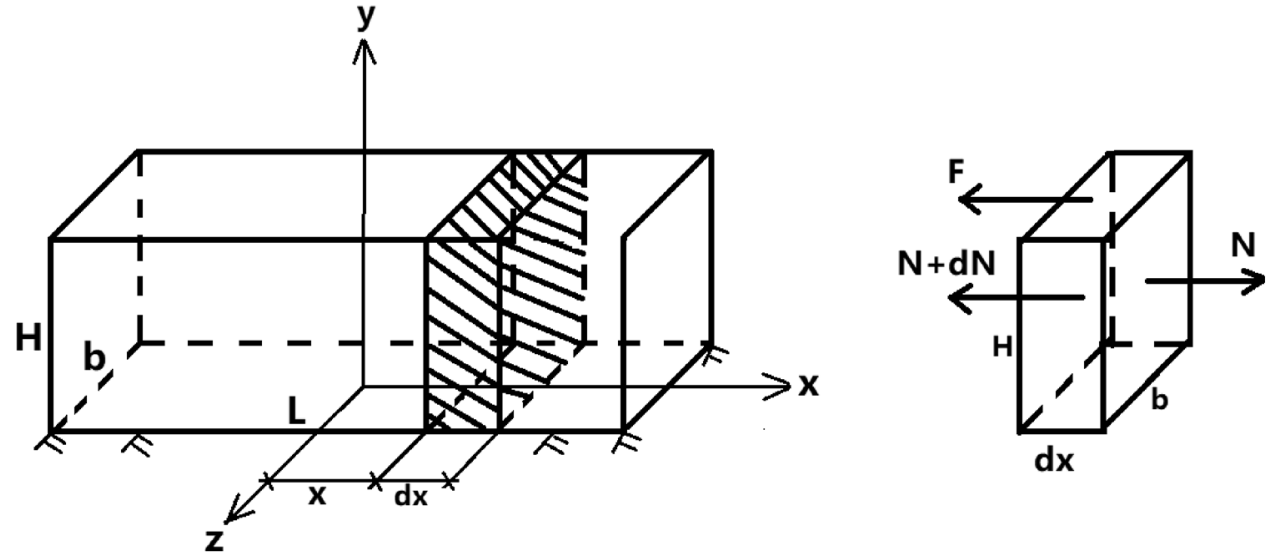
The XFEM function is a stress- and strain-based fracture initiation criterion, while the criterion for simulating crack extension is the maximum principal stress criterion (see Eq. 2) The crack extension invokes a degradation treatment where the enriched unit has a binding response, and the degradation process starts when the stress satisfies the criterion for crack extension. The fracture criterion for the start of microcrack extension is that $f$ reaches 1.0.

$f=\left\{\frac{\left\langle\sigma_{\max }\right\rangle}{\sigma_{\max }^{0}}\right\},\left\langle\sigma_{\max }\right\rangle=\left\{\begin{array}{ll}0, & \sigma_{\max }<0 \\ \sigma_{\max }, & \sigma_{\max }>0\end{array}\right\}$

where $\sigma_{\max }$ is the maximum critical principal stress, MPa.

The damage evolution criterion represents the damage evolution of the surface with binding behavior through the damage parameter $D$. D represents the average value of all damage intersecting the crack surface and the crack cell boundary, with only two values of 0 and 1 , increasing from 0 to 1 representing the damage evolution process.

\subsubsection{Pavement model}

The implementation of the analysis of reflective crack expansion behavior of asphalt pavements under dry shrinkage in ABAQUS relies mainly on the XFEM module, where the displacement field is constructed by selecting a special crack tip stress asymptotic function that allows the approximation function to exist in a form independent of the mesh division, followed by the definition of additional degrees of freedom to realize the discontinuity generated by the crack opening. The gaps between coarse and fine aggregates within the asphalt mixture inevitably lead to the presence of micro-cracks in the asphalt structural layer [28]. Therefore, in this paper, the behavior of reflected cracks in Semi-rigid type base asphalt pavements under dry shrinkage stresses is analyzed by two-dimensional modeling with the following assumptions:

(1) All layers of asphalt pavement materials are linearly elastic.

(2) The asphalt pavement layers are completely continuous.

(3) The force and deformation of the base layer under the action of the internal and external moisture gradient is a state of uniform change in the whole section.

(4) Pre-cracking at the central position of the Semi-rigid type base layer, and the pre-cracking extends to the bottom of the surface layer. In which, the length of the pre-crack of Semi-rigid type base layer is set to $20 \mathrm{~mm}$.

The Semi-rigid type base pavement models of cementstabilized gravel, cement-lime-stabilized gravel and limestabilized soil were established by controlling the material viscoelastic parameters, equivalent values of dynamic modulus of the material, the dry shrinkage coefficient of the material and the amount of water content variation through ABAQUS finite element analysis software. Considering the difference in temperature and load frequency at different depths of the pavement structure, the modulus of the asphalt layer is not uniform at different depths. Therefore, the concept of "modulus field" is introduced to equate the effect of temperature and load into the change of material modulus. The modulus field of the asphalt layer was calculated in combination with a study related to the modulus of asphalt mixture [29] by Eq. 3 .

$E^{*}=\alpha+\frac{\beta}{\left[1+\left(f_{c} / f^{\prime}\right)^{k}\right]^{m / k}}$

$f^{\prime}=a_{T} f, f=\frac{1}{2 \pi t}$

$\lg a_{T}=\frac{-c_{1}\left(T-T_{0}\right)}{c_{2}+\left(T-T_{0}\right)}$

where $E^{*}$ is the asphalt mixture modulus, $\mathrm{MPa} ; f_{c}$ is the frequency-dependent position parameter, $\mathrm{Hz} ; f^{\prime}$ is the scaling frequency, $\mathrm{Hz} ; a_{T}$ is the temperature-dependent displacement factor; $f$ is the load frequency, $\mathrm{Hz} ; t$ is the time of action of the load; $\alpha, \beta$ is the dynamic modulus parameter; $m, k$ is the shape parameter.

Due to the vertical shear stresses and the tensile stresses at the bottom of the base layer generated by the traffic load near the road median are greater than those generated when the road is on both sides, the traffic in the center of the road has a more adverse effect on the pavement structure damage [30]. Therefore, the model is taken at the axle cut, the $2 \mathrm{D}$ modeling length is $20 \mathrm{~m}$, the depth is taken as $2 \mathrm{~m}$. The asphalt pavement model is shown in Fig. 2.

The design parameters in the current asphalt pavement design index system are mostly static parameters, while the material modulus needs to conform to the real mechanical properties of the pavement. Considering that the performance of Semi-rigid subgrade materials changes greatly during the use of asphalt pavement, the fatigue test results of Semi-rigid subgrade materials are used to determine the effective modulus value of Semirigid subgrade by taking the stage transition point $(50 \%$ of fatigue life) of dynamic bending and tensile modulus decay curve as the characteristic point [31] and combining the temperature-load factor equivalent material modulus formula (see Eq. 3). Meanwhile, the effective values of the dry shrinkage coefficient, water content variation and resistance coefficient of the subgrade materials were determined with reference to the drying shrinkage versus 
Fig. 2 Asphalt pavement models

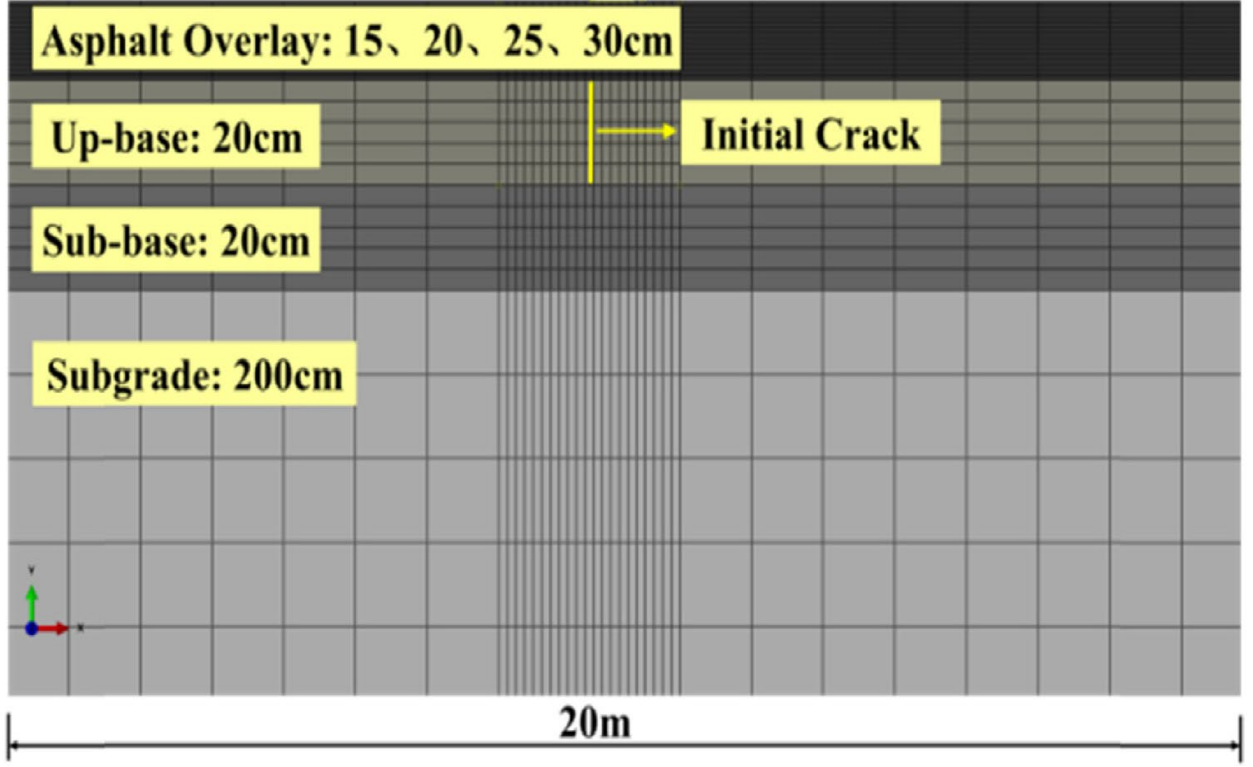

Table 1 Pavement structure layer correlation coefficients

\begin{tabular}{lcclccc}
\hline Structural layer & Thickness/mm & $\begin{array}{l}\text { Elastic } \\
\text { modulus/ } \\
\text { MPa }\end{array}$ & Poisson ratio & $\begin{array}{l}\text { Dry shrinkage } \\
\left.\text { coefficient/(10 }{ }^{-6}\right)\end{array}$ & $\begin{array}{l}\text { Uniform variation of } \\
\text { moisture content/\% }\end{array}$ & $\begin{array}{l}\text { Horizontal deformation } \\
\text { resistance coefficient }\end{array}$ \\
\hline Surface layer & 300 & 3000 & 0.25 & - & - & 1.3 \\
Up-base & 200 & 12000 & 0.25 & 90 & 3.0 & 1.3 \\
Sub-base & 200 & 8500 & 0.35 & - & - & 1.3 \\
Subgrade & 2000 & 80 & 0.40 & - & - \\
\hline
\end{tabular}

Table 2 Coordinates of dry shrinkage stress action

Regional maximum stress location $x=1 \quad x=3 \quad x=5 \quad x=7 \quad x=9$

water loss curves of the Semi-rigid subgrade materials in previous studies [32]. The calculated parameters for each layer of the asphalt pavement structure are shown in Table 1.

According to the above assumptions, the Semi-rigid type base is considered to be in a uniform state under the action of dry shrinkage stresses, and the dry shrinkage stresses in the base layer only have numerical fluctuations along the tangential direction of the road surface, while they are uniformly distributed in the normal direction.Therefore, the Semi-rigid type base is divided into 10 regions of $2 \mathrm{~m}$ in length, and the dry shrinkage stresses in each region are considered to be uniformly distributed tangentially and symmetrical about the central position of the base. The coordinates of the corresponding action points (Regional maximum stress location) of the dry shrinkage stress are shown in Table 2 below. The schematic diagram of dry shrinkage stress loading of Semi-rigid type base is shown in Fig. 3.

\section{Results and discussions}

\subsection{Formula for calculating the dry shrinkage stress in the base}

As can be seen from Fig. 1, the horizontal direction of the base is subjected to both dry shrinkage traction force and aggregate friction force, and is in equilibrium. The model micro-element section is intercepted, and the left and right sides of the micro-element are subjected to dry shrinkage traction, and the upper and lower sides are subjected to aggregate friction, The numerical formula for calculating the dry shrinkage stress in Semi-rigid type base is now derived from the force derivation of the microelement.The specific steps are as follows.

(1) According to the horizontal equilibrium conditions, establish the mechanical equilibrium equation.

\section{SN Applied Sciences}


Fig. 3 Schematic diagram of base layer dry shrinkage stress loading

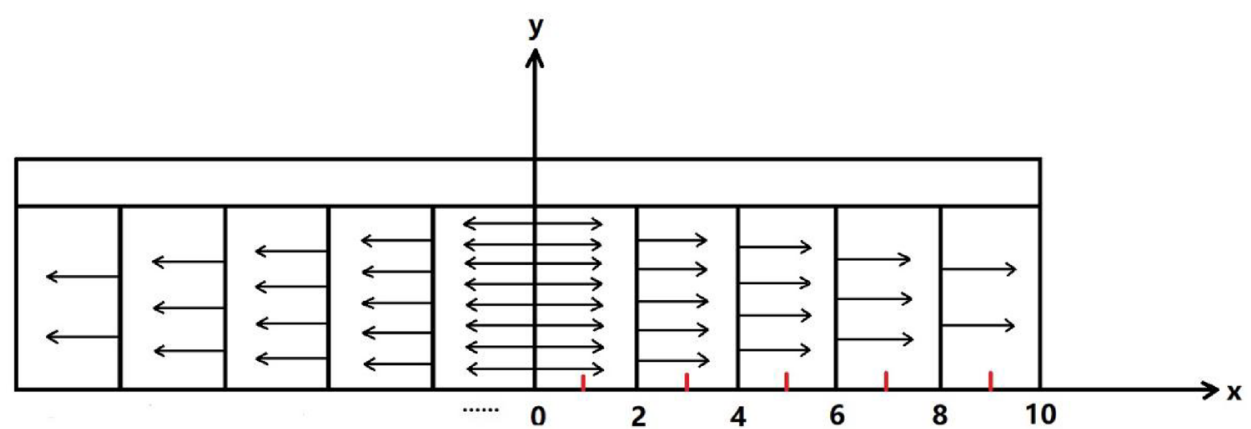

$\Rightarrow \frac{d \sigma_{x}}{d x}=\frac{\mu u}{h}$

where $\sigma_{x}=$ Dry shrinkage stress; $A=$ Area of dry shrinkage traction effect; $f=$ Frictional stress; $A_{f}=$ Frictional stress area of action; $\mu=$ Horizontal deformation resistance coefficient; $u=$ Uncoordinated dry shrinkage deformation due to difference in humidity inside and outside the substrate.

(2) The uncoordinated dry shrinkage deformation due to the difference in humidity inside and outside the substrate includes free and restrained displacements.

$u=u_{d}+\alpha_{d} \Delta m x$

$\Rightarrow \frac{d u}{d x}=\alpha_{d} \Delta m+\frac{d u_{d}}{d x}$

$\Rightarrow \frac{d^{2} u}{d x^{2}}=\frac{d^{2} u_{d}}{d x^{2}}$

where $u_{d}=$ Free displacement; $\alpha_{d}=$ Dry shrinkage factor; $\Delta m=$ Amount of uniform change in moisture content.

(3) From axial tensile Hooke's law, derive the intrinsic relationship between dry shrinkage incongruent deformation and dry shrinkage stress.

$\sigma_{x}=E \varepsilon_{x}=E \frac{d u_{d}}{d x}$
$\Rightarrow \frac{d^{2} u}{d x^{2}}-\frac{\mu}{E h} u=0$

$\Rightarrow \frac{d \sigma_{x}}{d x}=E \frac{d^{2} u_{d}}{d x^{2}}=E \frac{d^{2} u}{d x^{2}}$

where $E=$ Modulus of elasticity of base material; $\varepsilon_{x}=$ Dry shrinkage uncoordinated strain.

(4) From Eqs.10, 15, the formula for calculating the uncoordinated deformation of Semi-rigid type base is obtained.

$E \frac{d^{2} u}{d x^{2}}-\frac{\mu}{h} u=0$

Equation 17 is a second-order linear chi-square differential equation, where each constant coefficient in the second-order differential equation is: $1,0,-\frac{\mu}{E h}$, The characteristic roots are:

$r_{1}=\sqrt{\frac{\mu}{E h}}, r_{2}=-\sqrt{\frac{\mu}{E h}}, r_{1} \neq r_{2}$

The general solution for the basal incoherent deformation is:

$u=C_{1} e^{r_{1} x}+C_{2} e^{r_{2} x}$

where $C_{1}, C_{2}=$ The coefficient to be determined in the general solution of the base incoherent deformation.

Substituting the boundary conditions: $x=0, u=0 ; x=\frac{1}{2}, \sigma_{x}=0$, The equation for the uncoordinated deformation of the Semi-rigid type base is obtained as follows:

$u=\frac{\alpha_{d} \Delta m}{\sqrt{\frac{\mu}{E h}}} \cdot \frac{e^{\sqrt{\frac{\mu}{E h}} x}-e^{-\sqrt{\frac{\mu}{E h}} x}}{e^{\sqrt{\frac{\mu}{E h}} \frac{1}{2}}+e^{-\sqrt{\frac{\mu}{E h}} \frac{1}{2}}}$

(5) From Eqs. 11, 14 and 20, the formula for calculating the value of dry shrinkage stress in Semi-rigid type base is derived as follows: 
$\sigma_{x}=E \alpha_{d} \Delta m\left(\frac{e^{\sqrt{\frac{\mu}{E h}} x}+e^{-\sqrt{\frac{\mu}{E h}} x}}{e^{\sqrt{\frac{\mu}{E h}} \frac{1}{2}}+e^{-\sqrt{\frac{\mu}{E h}} \frac{1}{2}}}-1\right)$

Considering that the whole section of the Semirigid type base is in a uniform stress state, and the basic assumption that the dry shrinkage stress only fluctuates along the tangential direction of the road surface and is uniformly distributed in the normal direction, the dry shrinkage stress in the internal center of the Semi-rigid type base is maximum. Therefore the value of dry shrinkage stress at $x=0$ is the maximum:

$\sigma_{x}=E \alpha_{d} \Delta m\left(\frac{2}{e^{\sqrt{\frac{\mu}{E h}} \frac{1}{2}}+e^{-\sqrt{\frac{\mu}{E h} \frac{1}{2}}}-1}\right)$

From the derived base dry shrinkage stress calculation formula Eqs. 21, 22, it can be seen that the dry shrinkage stress of Semi-rigid type base course is related to the elastic modulus of base course material, dry shrinkage coefficient, uniform variation of moisture content, horizontal deformation resistance coefficient, and structural dimensions of Semi-rigid type base base course.

The dry shrinkage stress values in each area of the base were calculated by substituting the relevant parameters of the pavement structure (see Table 1) into Eq. 22 and are shown in Table 3.

\subsection{Asphalt pavement dry shrinkage reflection cracking behavior}

In order to clarify the dry shrinkage reflection cracking mechanism of Semi-rigid type base asphalt pavements, the dry shrinkage reflection cracking pathways of different asphalt pavements, stress distribution at the tip of reflection cracks and the influence of relevant parameters on the dry shrinkage reflection cracking behavior of pavements was investigated.

Table 3 Values of dry shrinkage stress in each region of Semi-rigid type base

Regional maximum stress location $x=1 \quad x=3 \quad x=5 \quad x=7 \quad x=9$

\begin{tabular}{lllllll}
\hline Dry shrinkage stress value/MPa & 0.38 & 0.36 & 0.33 & 0.31 & 0.28
\end{tabular}

\subsubsection{Pavement dry shrinkage reflection cracking pathways}

The total duration of the numerical simulation was set to 1 by ABAQUS finite element software [33], and the dry shrinkage crack extension behavior of the Semi-rigid type base was analyzed by the simulation results of each stage of the analysis step.The extension behavior of the cracks was analyzed by selecting the STATUEXFEM field output graph in ABAQUS, as shown in Fig. 4.

From Fig. 4, it can be seen that under the action of the dry shrinkage stress, the micro-cracks within the Semirigid type base underwent a two-way extension behavior, mainly manifested by the reflection extension behavior into the surface course and the cracking phenomenon into the lower base layer. The micro-cracks in the Semi-rigid type base did not immediately produce crack extension behavior under the action of dry shrinkage stress. Probably at the Step time $=0.35 \mathrm{~T}$, the micro-cracks in the base course extended and cracking behavior to the sub-base occurred.At the Step time $=0.79 \mathrm{~T}$, the cracks start extend to the surface layer and form reflection cracks.At the Step time $=0.87 \mathrm{~T}$, the reflection cracks penetrated the whole surface layer and pavement damage occurred.In this case, the base cracking cracks below are nearly at a standstill during the extension of the micro-cracks upward surface layers. The reason why microcracks extend into the subgrade below first is that the modulus of the subgrade material is much higher than that of the surface material. Although the high modulus subgrade has sufficient stiffness to withstand the load, it is difficult to resist the spatial deformation. And asphalt as the binder material of the pavement structure, the adhesion of asphalt ensures the resistance to deformation of the surface layer. It can be seen that the microcracks will first extend into the base layer where the stiffness is greater. With the increase of dry shrinkage stresses with uneven gradient distribution, the micro cracks extend to the surface layer to form reflection cracks.

Although the extension of micro-cracks to both the surface and the base layer occurs, there is a certain difference in the degree of crack extension, specifically: the degree of reflection expansion of micro-cracks in the surface layer is greater than the degree of continued cracking in the base layer, and once the reflection crack appears in the surface layer, it will quickly penetrate the entire surface layer.The time duration from the start of the reflection crack in the surface layer to the penetration of the entire surface layer is only about $1 / 10$ of the total time duration of the extension of micro-cracks in the base layer. During the expansion of micro-cracks in the base, the extension of micro-cracks to the base layer below does not occur as a complete cracking behavior, and the function of the 


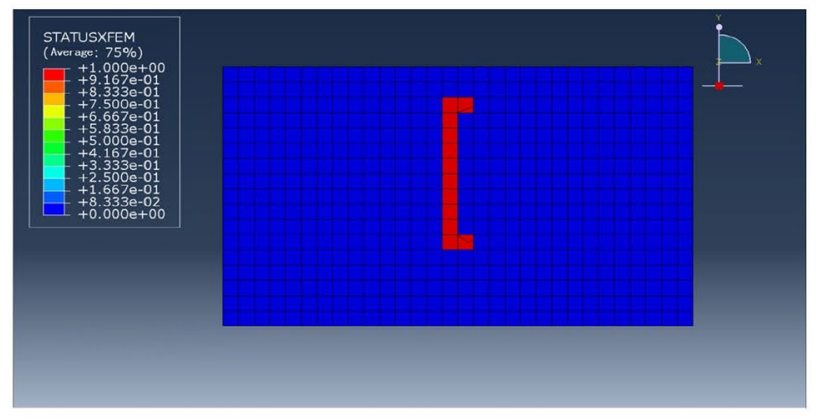

(a) Step time=0.35

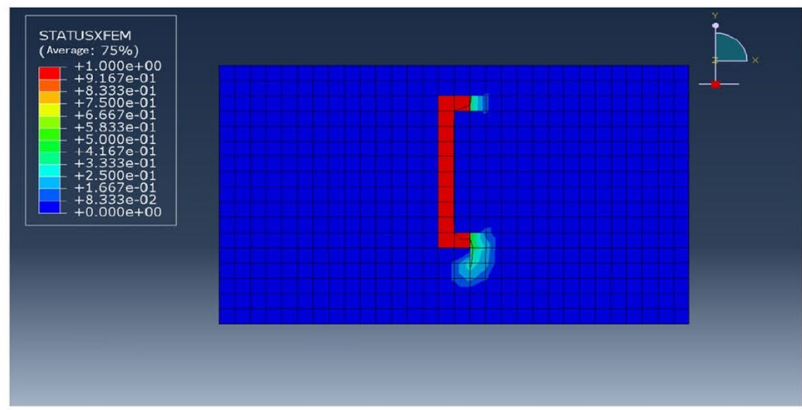

(c) Step time=0.79

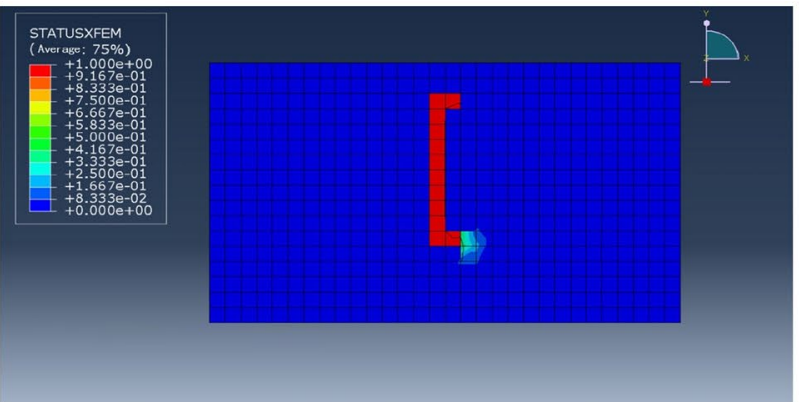

(b) Step t ime $=0.57$

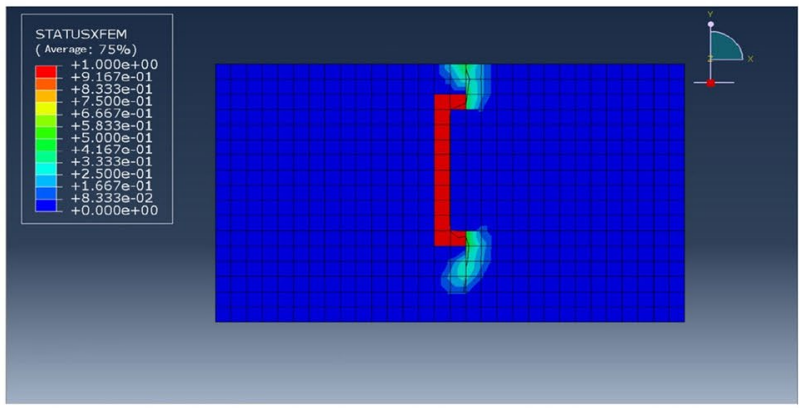

(d) Step time=0.90

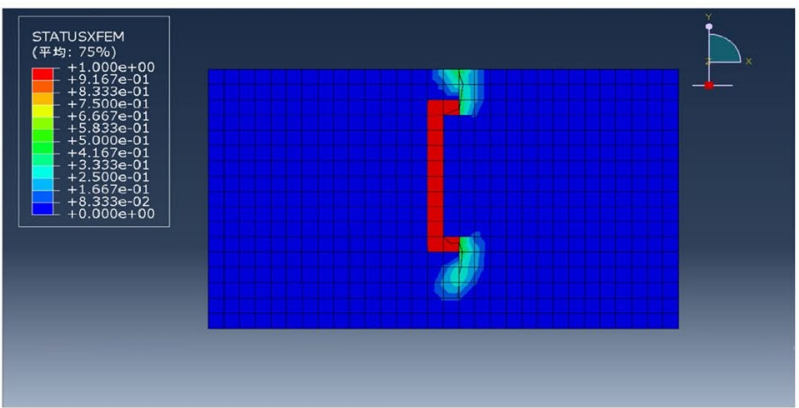

(e) Step time=1

Fig. 4 Stage diagram of dry shrinkage crack extension behavior

structural layer is not completely destroyed. While the reflection of micro-cracks to the upper side layer causes penetration cracks and the overall damage of the surface layer occurs.Therefore, based on this damage mechanism, the relevant departments can carry out targeted and sequential maintenance of pavements with cracks as the main disease.

A graph of the elongation rate of micro-cracks in the base is established, as shown in Fig. 5.

From Fig. 5, it can be obtained that after the reflection cracks appear in the surface layer (analysis step = $0.78 \mathrm{~T}$ ), the extension rate of downward cracking of base micro-cracks gradually slowed down and finally came to a standstill.While the extension rate of reflection cracks in the surface layer became more and more rapid until the reflection cracks penetrated the whole surface layer (analysis step $=0.91 \mathrm{~T}$ ). During the whole process of microcrack extension, the difference between the extension rate of downward cracking and the extension rate of upward reflection gradually decreased (the length of the dark rectangular block in Fig. 4 gradually decreased), which shows that the extension of cracks in the base is mainly extended by the extension of reflective cracks in the surface layer as the main extension behavior.

The cracking degree of reflection cracks in the surface layer is much larger than that in the base layer, mainly because the thickness of the structural layer of the surface layer is too small. When reflection cracks appear in 
Fig. 5 Relative elongation rate of micro-cracks in the Semirigid type base
Relative elongation rate of microcracks in the Semirigid base

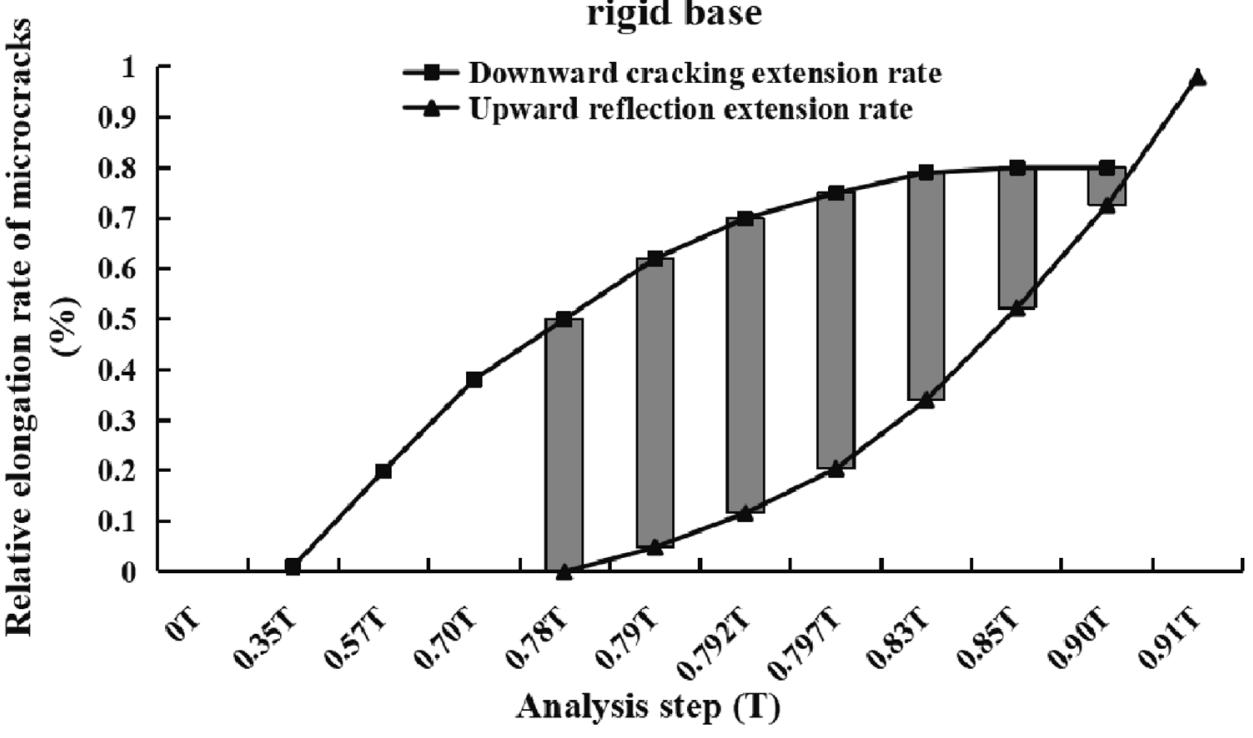

the surface layer, the stress concentration phenomenon appears at the crack tip, and the smaller thickness of the surface layer makes it difficult to resist the extension of the reflection cracks, so once the reflection cracks appear in the surface layer, it will be rapidly destroyed. Although it is difficult to coordinate the deformation due to the large stiffness of the subgrade resulting in microcracks extending to the subgrade first, the large thickness of the subgrade structure is the reason why the cracks do not crack to a significant extent within the subgrade.

\subsubsection{Stress distribution of dry shrinkage type crack tip of road surface}

The main stress map of the crack tip unit cell is selected in ABAQUS to analyze the crack tip stress distribution, and the details are shown in Fig. 6.

From Fig. 6 , it can be seen that the Semi-rigid type base layer under the action of dry shrinkage stress, the unit body around the crack showed the plane stress state of the main tensile stress.With the extension of the base microcrack, the stress response state of the surface and base changed.Before the extension of the crack, the stress variation was relatively gentle.When the extension of the crack started to occur, the stress state at the crack tip changed abruptly, as shown by the fact that the maximum tensile stress value increased nearly twice as much as before the cracking. As the cracks continued to extend, the stress increase value also became more and more obvious.

During the whole process of crack expansion, the maximum stress response region is at the tip of the micro-crack near the surface layer, and the position does not change, only the stress magnitude changed, while the minimum stress response region only changed in the upper layer. During the extension of the Semi-rigid type base microcracks, the region with obvious stress response is distributed at the crack tip location, and the stress state of the unit radiates from the crack tip to the surrounding ring to weaken. The stress in the middle area of the crack and the area without cracks was smaller, and the magnitude of stress variation in this area with crack extension was also smaller. Therefore, the stress value at the crack tip can be selected as the design value of the load bearing limitation for the structural performance calculation of the pavement with reflection crack damage.

By analyzing the degree of crack tip stress variation at different stages, a graph of the magnitude of crack tip stress response variation with respect to the analysis step is plotted, as detailed in Fig. 7.

From Fig. 7, it can be obtained that with the extension behavior of dry shrinkage micro-cracks in the base, the maximum stress response at the crack tip varied. This is manifested in four stages:

Stage 1. Crack extension has not yet occurred. The stress amplitude at the crack tip in this stage is relatively small and varies roughly linearly.

Stage 2. Micro-cracks start to extend to the base. The stress amplitude at the crack tip in this stage is significantly increased compared with stage one (uncracked), but the stress amplitude is not so drastic, and the stress increase also shows roughly linear growth.

Stage 3. The micro-cracks started to extend to the surface layer to form reflection cracks, and the stress state at the crack tip at this time was nearly step-like abruptly growing.In stage 3 , the crack tip stress amplitude has 


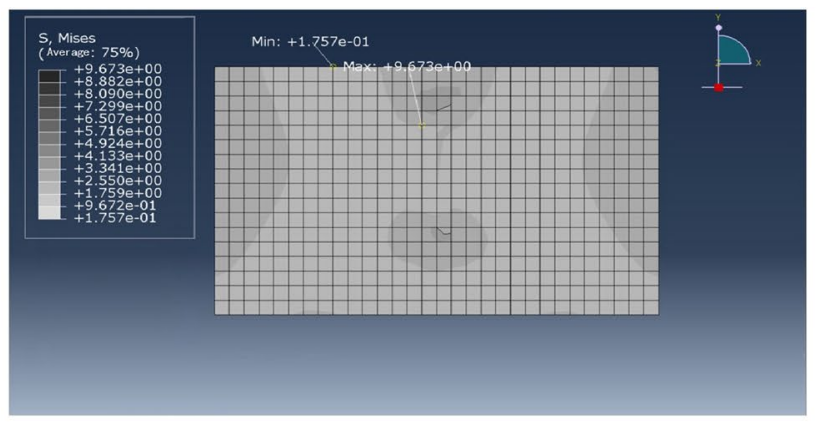

(a) Step time=0.35

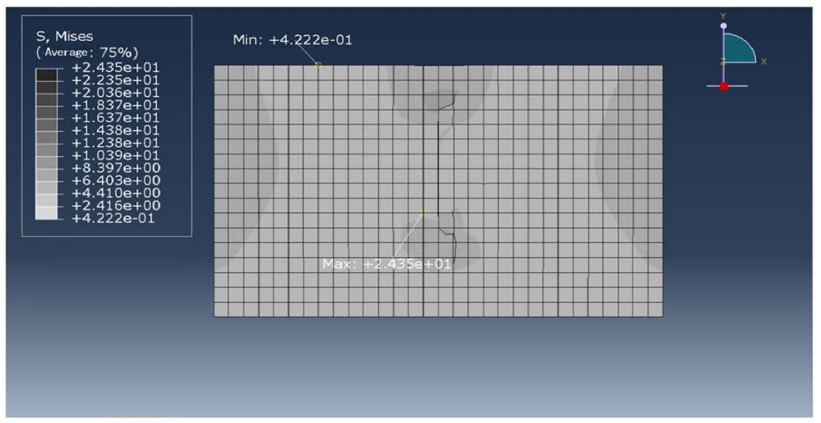

(c) Step time=0.79

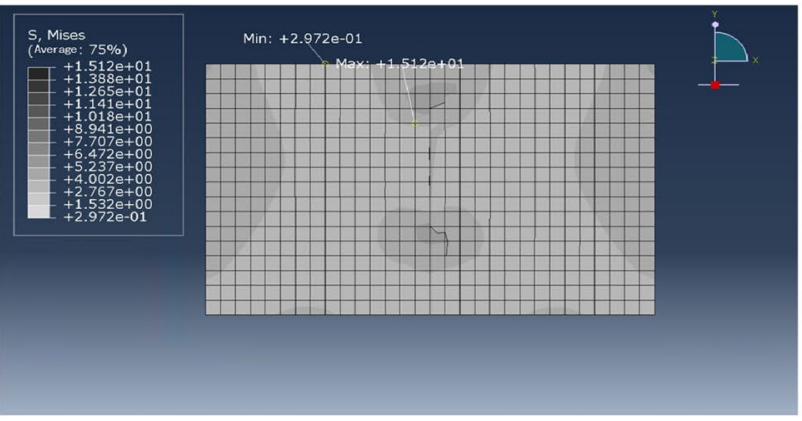

(b) Step time $=0.57$

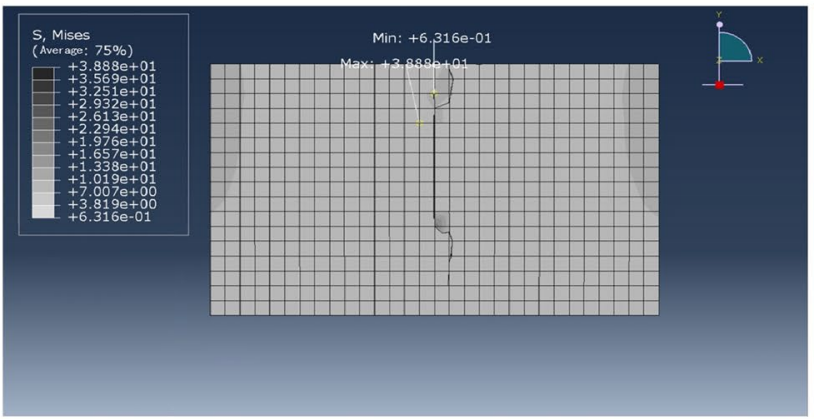

(d) Step time=0.90

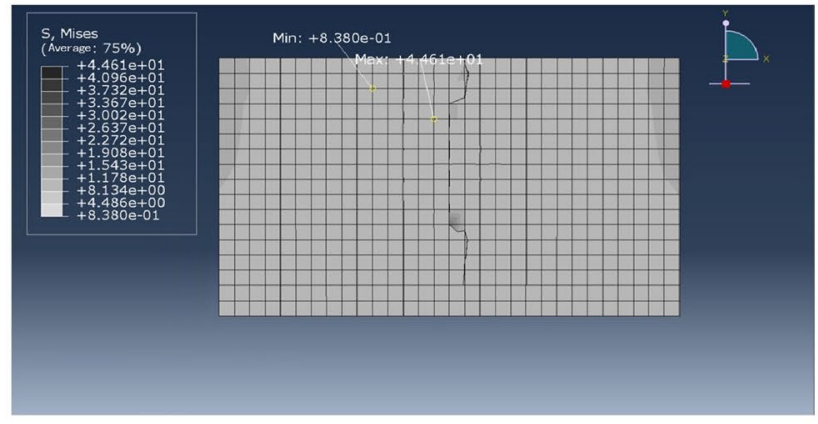

(e) Step time=1

Fig. 6 Stress response phase diagram of dry shrinkage type cracks

a very obvious increase, roughly exponential increase trend, and the crack tip stress increase in this stage accounts for about $1 / 2$ of the whole process of crack extension.

Stage 4. The reflection crack penetrates the whole surface layer.The crack tip stress amplitude at this stage tends to level off, the maximum value of the crack tip stress appeared, and the subsequent crack tip stress does not continued to grow, marking the occurrence of damage to the pavement.

A polynomial fit to the crack tip stress scatter of each stage reveals that the fit line in Fig. 7 has a high similarity to the full process tip stress response case, which can reach
$R^{2}=0.9886$. The fitted equation is: $y=-25.873 x^{4}+134.13 x^{3}$ $-110.15 x^{2}+49.348 x-0.2908$.Thus, the prediction of the stress response for the whole stage could be achieved by fitting the curve in Fig. 7. That is, when cracks start to appear in the Semi-rigid type base, the stress value at the crack tip when the final reflective crack penetrated the surface is obtained by measuring the time of crack extension cracking and substituting into the fitting equation.

\subsubsection{Effect of relevant parameters on the dry shrinkage reflection cracking behavior of pavements}

3.2.3.1 Modulus of semi-rigid type base material Controlling the thickness of the base layer is constant, the elas- 
Fig. 7 Stress response phase diagram of the crack tip
Variation of stress response value at the crack tip

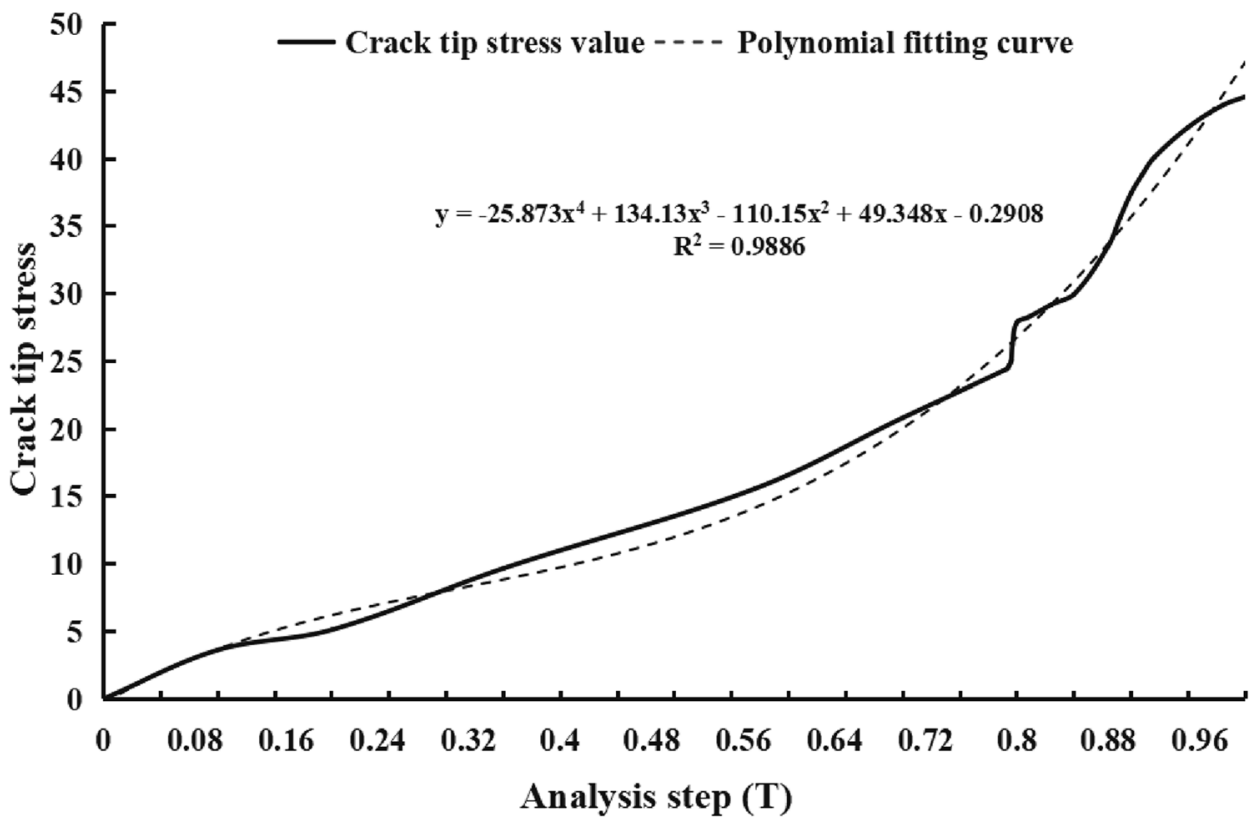

Table 4 Dry shrinkage stress for different elastic modulus(MPa)

\begin{tabular}{llllll}
\hline Regional maximum stress & $x=1$ & $x=3$ & $x=5$ & $x=7$ & $x=9$
\end{tabular} location (MPa)

\begin{tabular}{llllll}
\hline Elastic modulus $=8000$ & 0.35 & 0.33 & 0.30 & 0.28 & 0.25 \\
Elastic modulus $=10000$ & 0.38 & 0.36 & 0.33 & 0.31 & 0.28 \\
Elastic modulus $=12000$ & 0.40 & 0.38 & 0.35 & 0.33 & 0.30 \\
\hline
\end{tabular}

tic modulus of Semi-rigid type base was selected as 8000 $\mathrm{MPa}, 10000 \mathrm{MPa}$ and $12000 \mathrm{MPa}$ respectively. The dry shrinkage stress values are calculated by substituting into Eq.Il as shown in Table 4. Meanwhile the extension rate of dry shrinkage reflection cracks for different elasticity modulus of substrate materials is plotted, see Figure 8.
Fig. 8 Elongation rate of dry shrinkage reflection cracks for different substrate elastic modulus

\section{Elongation rate of dry shrinkage reflection cracks for different substrate elastic modulus}

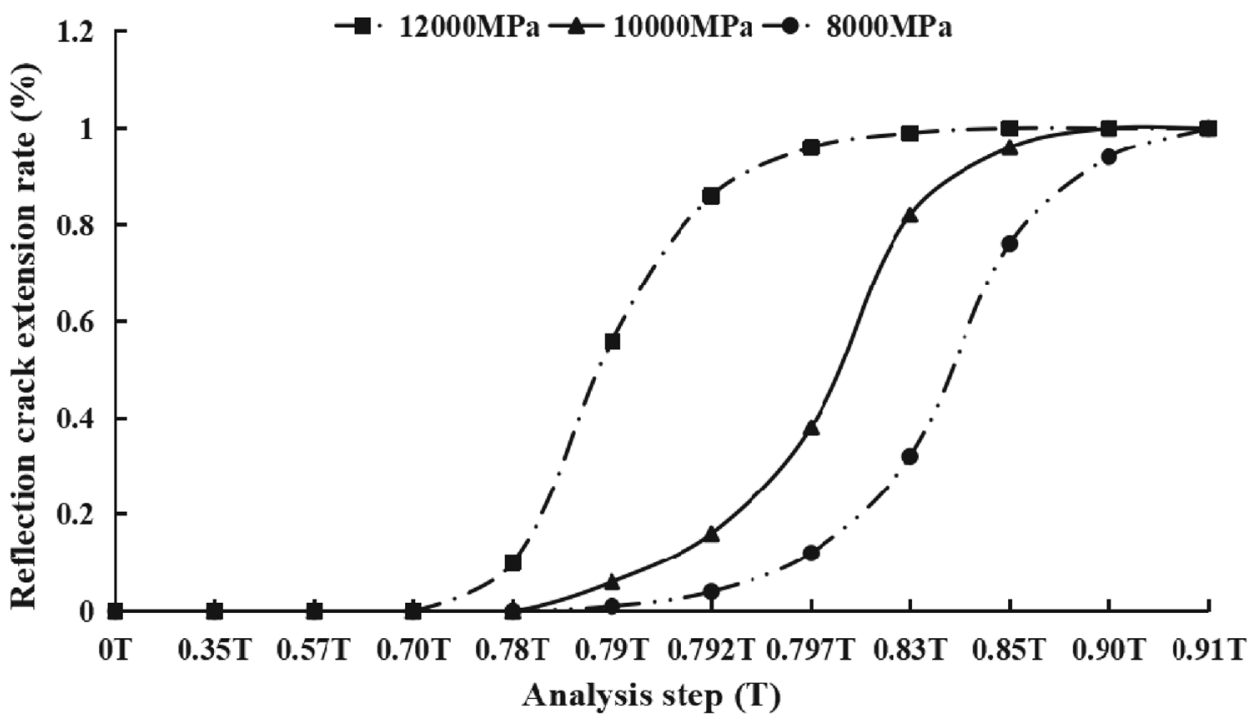


From Figure 8 , it can be obtained that as the elastic modulus of the Semi-rigid type base material grew, the dry shrinkage stress also increases, and reflection cracks would appear earlier in the asphalt pavement surface layer. Specifically, when the $E=12000 \mathrm{MPa}$ of the base material , reflection cracks started to appear at Step time $=0.70 \mathrm{~T}$, while when the $E=8000 \mathrm{MPa}$ and $\mathrm{E}=10000 \mathrm{MPa}$ of the base material, reflection cracks started to appear only at about Step time $=0.80 \mathrm{~T}$.

With the increased modulus of elasticity of Semi-rigid subgrade, the extension rate of reflection cracks increased significantly and penetrated the whole surface layer rapidly. Specifically, the slope of the reflective crack extension rate curve of the base with modulus of $12000 \mathrm{MPa}$ is larger than that of the base layer with modulus of $10000 \mathrm{MPa}$ and $8000 \mathrm{MPa}$. The time interval of the former reflection crack penetrating the surface layer was roughly $T=0.097 \mathrm{~T}$, while the time interval of the latter two was $T=0.12 \mathrm{~T}$ and $\mathrm{T}=$ $0.13 \mathrm{~T}$ respectively.

In the design of Semi-rigid type base base material, it is not appropriate to choose a larger or smaller elasticity modulus of the base, should take into account the road settlement, bearing and other structural requirements, choose the appropriate elasticity modulus of Semi-rigid type base material.

3.2.3.2 Semi-rigid type base thickness The modulus of the Semi-rigid type base material was controlled to be constant, and the thickness of the Semi-rigid type base was selected as $350 \mathrm{~mm}, 400 \mathrm{~mm}$ and $450 \mathrm{~mm}$ respectively. The dry shrinkage reflective crack extension rate and dry shrinkage reflective crack tip stress response are plotted for different substrate thicknesses, as shown in Figs. 9, 10.

From Figs. 9, 10, it can be obtained that the base layer thickness increased by $50 \mathrm{~mm}$ and $100 \mathrm{~mm}$ respectively, and the extension rate of reflection cracks slowed down, and the time interval of reflection cracks penetrating the whole surface layer increased by $0.09 \mathrm{~T}$ and $0.05 \mathrm{~T}$ respectively.However, the time of reflection cracks appearing in different substrate thicknesses was nearly the same, and the reflection cracks occurred roughly at Step time $=0.79$ $\mathrm{T}$.

The base layer thickness increased by $50 \mathrm{~mm}$ and $100 \mathrm{~mm}$ respectively, and the reflection crack tip stress decreased by $2.95 \%$ and $5.91 \%$ respectively at the final damage.However, during the whole process of reflection crack extension, the variation of the tip stress of cracks with different base layer thickness tends to be consistent.Specifically, the tip stress changed gently when the crack did not extend; the tip stress jumped in steps when the crack extends to the surface layer to form a reflection crack, the maximum stress appeared after the crack penetrated the whole surface layer and the tip stress increase stabilized.

The increase in thickness of Semi-rigid type base makes the reflection crack extension rate and stress state at the crack tip weaken, but the variability of reflection crack extension behavior for different base thickness is slight.

3.2.3.3 Variation of moisture content and dry shrinkage factor Three Semi-rigid type base materials, cementstabilized gravel, cement-lime-stabilized gravel and lime-
Fig. 9 Elongation rate of dry shrinkage reflection cracks for different substrate thickness

\section{Elongation rate of dry shrinkage reflection cracks for different substrate thickness}

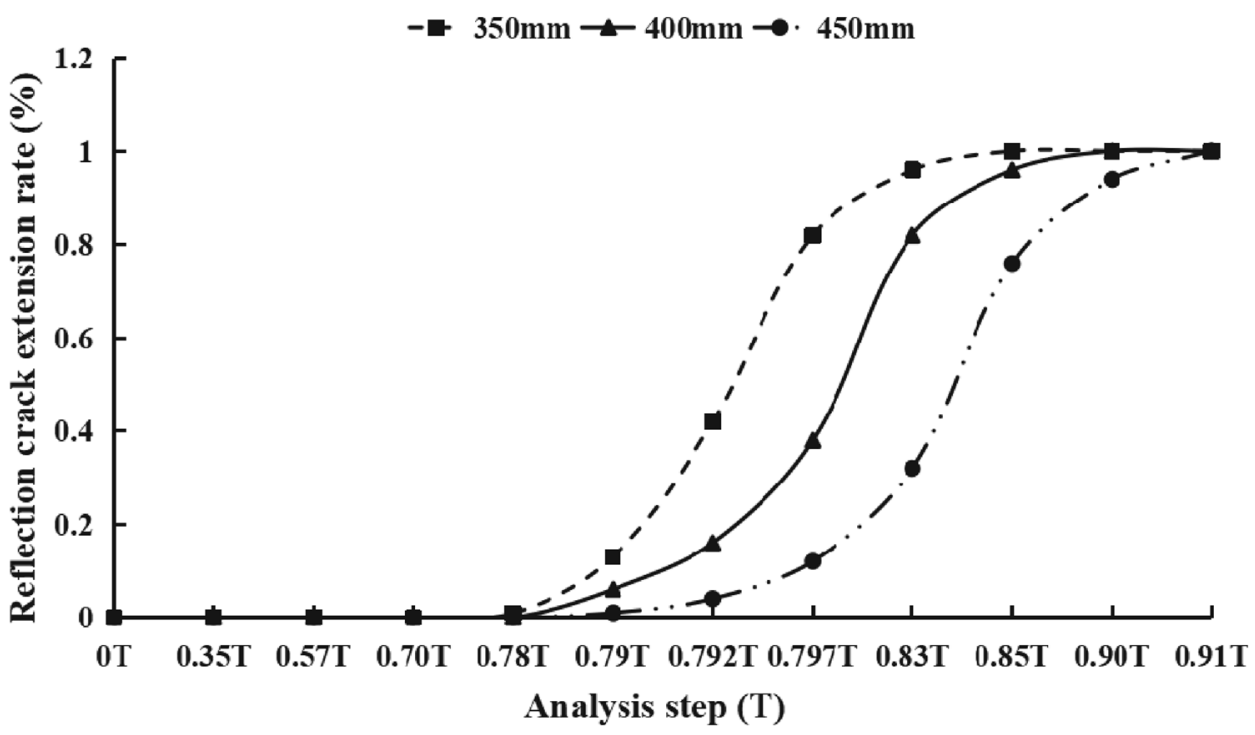

SN Applied Sciences A SPRINGER NATURE journal 
Fig. 10 Stress values at the tip of dry shrinkage reflection cracks for different substrate thicknesses
Stress values at the tip of dry shrinkage reflection cracks for different substrate thicknesses

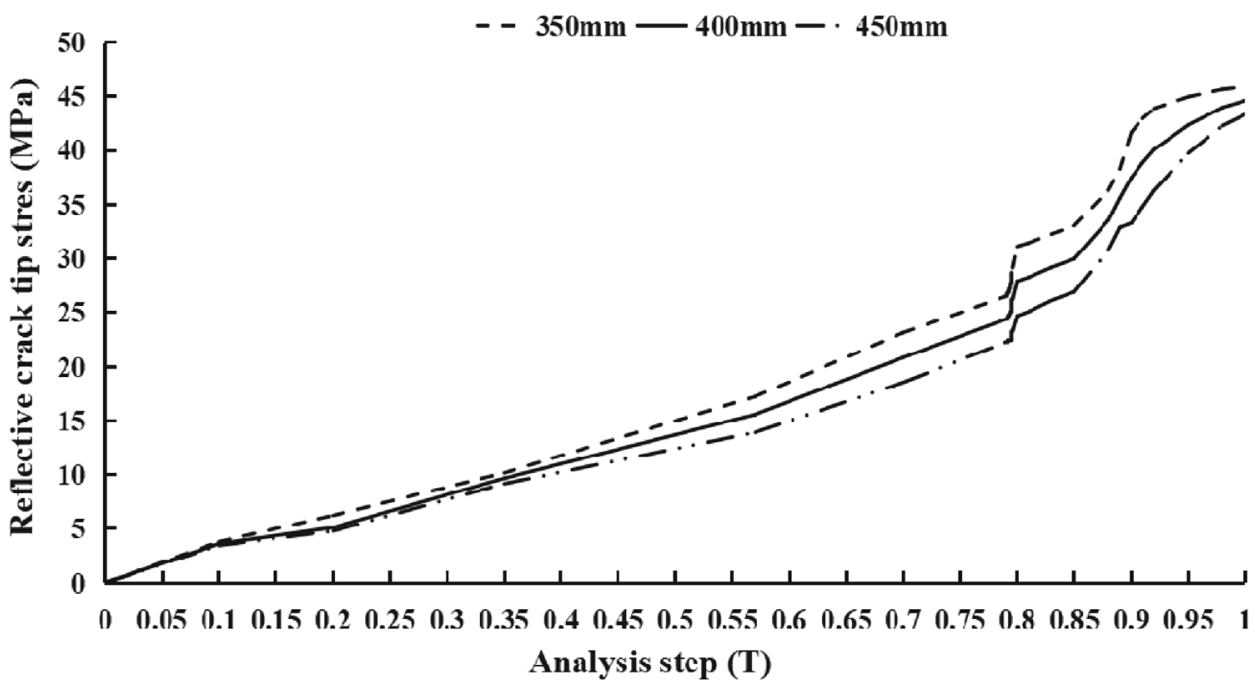

stabilized soil, were selected to study the effect of the dry shrinkage coefficient of the base materials on the extension behavior of dry shrinkage reflective cracks,and to investigate the relationship between different Semi-rigid type base layer variation of moisture content and the interval of dry shrinkage reflection cracks penetrating the surface layer.The extension rate of dry shrinkage reflective cracks with different base dry shrinkage coefficients and the interval of dry shrinkage reflective cracks penetrating the surface layer with different variation of moisture content were plotted,as shown in Figs. 11, 12, respectively.
From, Figs. 11, 12 it can be obtained that the order of occurrence of reflective cracks in the surface layer: lime stabilized soil, cement-lime stabilized gravel, cement stabilized gravel. The interval of reflection cracks penetrating the whole surface layer leading to structural damage of the pavement is: cement stabilized gravel<cement lime stabilized gravel < lime stabilized soil.

The lime stabilized soil is the earliest to have reflective cracks in the surface layer due to its relatively large dry shrinkage coefficient, however, due to its greater flexibility, the lime stabilized soil has sufficient resistance to
Fig. 11 The extension rate of dry shrinkage reflective cracks with different base dry shrinkage coefficient

\section{Dry shrinkage reflection crack extension rate graph for different substrate dry shrinkage coefficients}

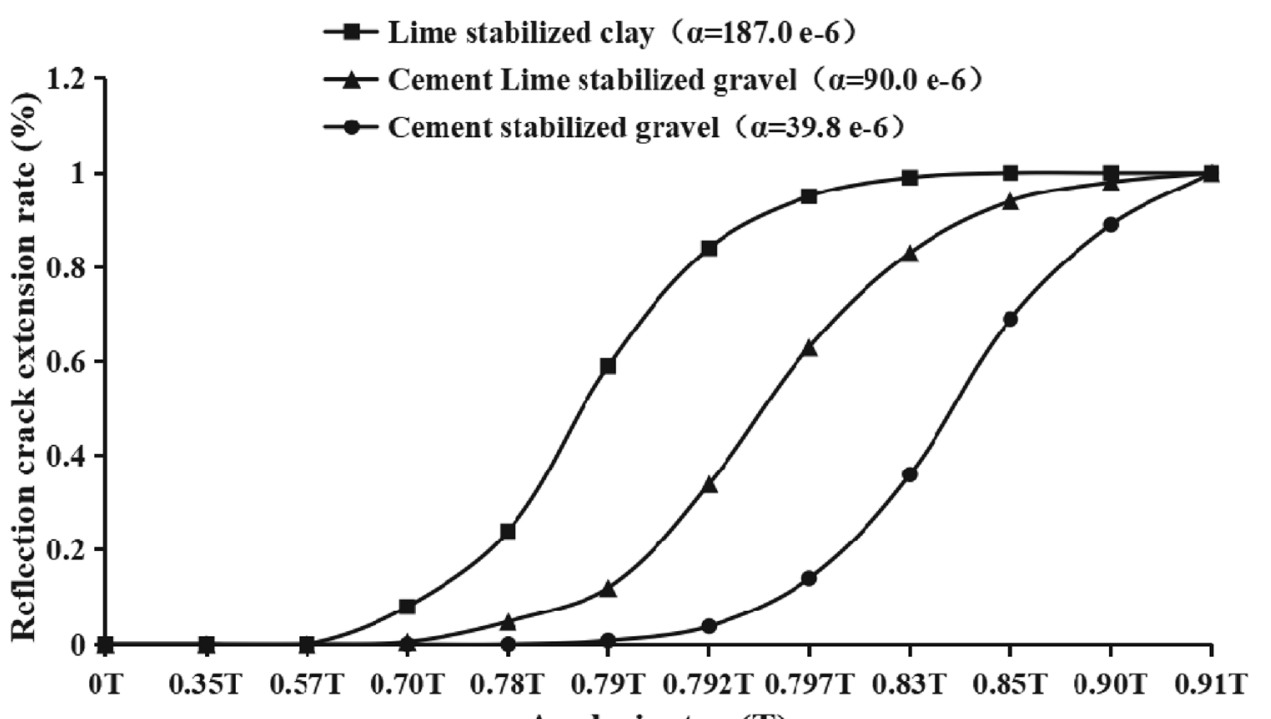

Analysis step (T) 
Fig. 12 The interval of cracks penetrating the surface layer with different variation of moisture content
Dry shrinkage reflection cracks through the surface layer time for different variation of moisture content

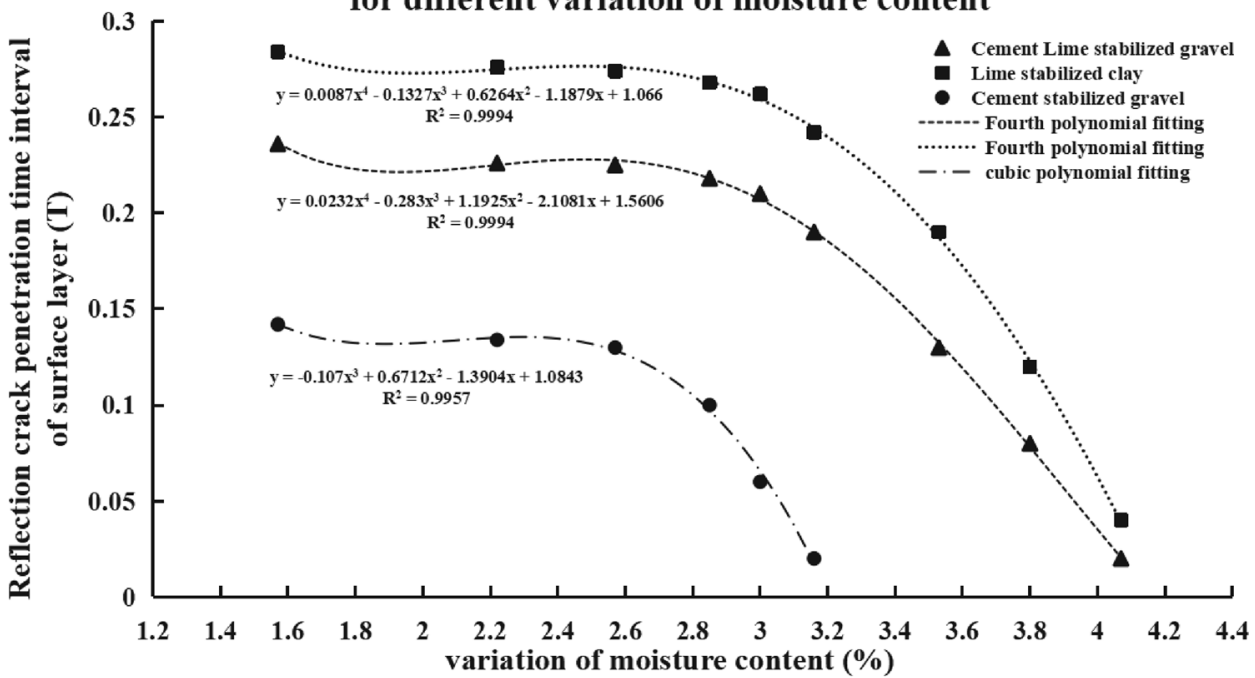

deformation due to dry shrinkage of the base, resulting in the longest interval of reflection cracks through the surface layer. The time interval of cracks through the surface layer of cement-lime-stabilized gravel base is only 0.05 T less than that of lime-stabilized soil, but the time of its reflection cracks appears is $0.13 \mathrm{~T}$ longer.

According to the trend of the fitted curves, it was found that in the three types of Semi-rigid type base layers, when the variation of moisture content was less than a certain value, the variation of the interval of dry shrinkage reflective cracks through the surface layer was not obvious, but when the variation of moisture content exceeded this boundary value, the interval of dry shrinkage reflective cracks penetrating the surface layer was shortened rapidly. Among them, the threshold value of water content variation is $2.87 \%$ for cement stabilized gravel base, $3.05 \%$ for lime stabilized soil base, and $2.58 \%$ for cement stabilized gravel base.The interval of cracks penetrating the surface layer of cement-lime-stabilized gravel base is only 0.05T lower than that of lime stabilized soil.However, the occurrence of reflection cracks in cement-lime stabilized gravel base is delayed by $0.13 \mathrm{~T}$.

Cement-lime-stabilized gravel base has the properties of lagging crack extension, extended interval of cracks penetrating the surface layer, and large range of allowable variation of moisture content, etc., which satisfies the design concept of road design in order to improve the whole life cycle of pavement, require the crack extension behavior to appear as slowly as possible and have a certain reaction time to repair and maintain it after the cracks appear. Considering the design requirements of deformation resistance and strong load-bearing of pavement subgrade, it is most suitable to choose cement-lime stabilized crushed stone subgrade in road projects where the difference of humidity inside and outside the subgrade causes uncoordinated dry shrinkage deformation, and try to control the change of moisture content of cement-lime stabilized crushed stone subgrade in the range of $2.2-3 \%$.

\section{Conclusions}

(1) This paper constructs the model of uncoordinated dry shrinkage deformation caused by the difference of moisture inside and outside the subgrade, and uses the theory of differential equations to derive the calculation formula of uneven gradient distribution of dry shrinkage stress in the subgrade (Eq. 22). The formula shows that the dry shrinkage stress of Semi-rigid type base course is related to the elastic modulus of base course material, dry shrinkage coefficient, uniform variation of moisture content, horizontal deformation resistance coefficient, and structural dimensions of Semi-rigid type base.

(2) Under the action of dry shrinkage stress, the microcracks within the Semi-rigid type base have a twoway expansion behavior, mainly manifested as: the cracking phenomenon to the bottom of the base layer, the extension behavior to the upper layer and the generation of reflective cracks.Moreover, the extension rate of reflection cracks in the surface layer is considerably greater than the crack cracking rate in the base layer.

(3) With the extension of the reflected cracks in the surface layer, the stress state at the crack tip changes abruptly and the stress increases obviously. The stress value at the tip of the crack is calculated by substitut- 
ing the time of reflection crack appearance into the linear fitting equation.

(4) Decreasing the modulus of the Semi-rigid type base material can retard the extension rate of the reflective cracks, and the variation of the base thickness has little effect on the extension behavior of the reflective cracks.

(5) The cement-lime-stabilized gravel base has the properties of lagging crack extension, extended crack penetration interval, and large allowable variation range of moisture content compared with lime stabilized soil base and cement-stabilized gravel base. Control of cement-lime-stabilized gravel base moisture content variation in the range of $2.2 \%-3 \%$ can effectively reduce the dry shrinkage reflection crack extension rate and crack-tip stress of the pavement.

Acknowledgements The authors wish to acknowledge Dr M. M. Xiao, Professor of road engineering, University of Shanghai Institute of Technology, for her help in interpreting the significance of the results of this study. Meanwhile the authors wish to thank the timely help given by W. Cheng in analyzing the large number of sample. Finally Funding from the SIT Institution is gratefully acknowledged.

Funding This research is supported by Shanghai Institute of Technology, Grant number 10000RMB.

Data availability and materials Some data, models, and code generated or used during the study appear in the submitted article. Some of the raw/processed data required to reproduce these findings cannot be shared at this time as the data also forms part of an ongoing study.

\section{Declarations}

Conflict of interest We declare that we have no financial and personal relationships with other people or organizations that can inappropriately influence our work.

Open Access This article is licensed under a Creative Commons Attribution 4.0 International License, which permits use, sharing, adaptation, distribution and reproduction in any medium or format, as long as you give appropriate credit to the original author(s) and the source, provide a link to the Creative Commons licence, and indicate if changes were made. The images or other third party material in this article are included in the article's Creative Commons licence, unless indicated otherwise in a credit line to the material. If material is not included in the article's Creative Commons licence and your intended use is not permitted by statutory regulation or exceeds the permitted use, you will need to obtain permission directly from the copyright holder. To view a copy of this licence, visit http://creativecommons. org/licenses/by/4.0/.

\section{References}

1. Ruiz-Riancho N, Saadoon T, Garcia A, Grossegger D, HudsonGriffiths R (2021) Optimisation of self-healing properties for asphalts containing encapsulated oil to mitigate reflective cracking and maximize skid and rutting resistance. Constr Build Mater 300:123879

2. Das A, Bhuyan MR, Khattak MJ, Zhang Q (2020) Mitigating reflective cracking in composite pavements through the use of a ductile concrete interlayer. Constr Build Mater 259:120383

3. Fang $\mathrm{H}$, Luo H, Zhu H (2016) The feasibility of continuous construction of the base and asphalt layers of asphalt pavement to solve the problem of reflective cracks. Constr Build Mater 119:80-88

4. Oshone M, Dave EV, Sias Jo E (2019) Asphalt mix fracture energy based reflective cracking performance criteria for overlay mix selection and design for pavements in cold climates. Constr Build Mater 211:1025-1033

5. Ji RY, Mandal T, Yin H (2020) Laboratory characterization of temperature induced reflection cracks. J Traffic Transp Eng (Engl Ed) 7(5):668-677

6. Pirmohammad S, Ayatollahi MR (2015) Asphalt concrete resistance against fracture at low temperatures under different modes of loading. Cold Reg Sci Technol 110:149-159

7. Gonzalez-Torre I, Calzada-Perez MA, Vega-Zamanillo A, CastroFresno D (2015) Evaluation of reflective cracking in pavements using a new procedure that combine loads with different frequencies. Constr Build Mater 75:368-374

8. Ji B (2015) Causes and prevention of reflection cracks in Semi-rigid type base asphalt pavement. China Technol Expo 23:115-115

9. Wang $X$, Zhong $Y$ (2019) Reflective crack in semi-rigid base asphalt pavement under temperature-traffic coupled dynamics using XFEM. Constr Build Mater 214:280-289

10. Wang X, Li K, Zhong Y et al (2018) XFEM simulation of reflective crack in asphalt pavement structure under cyclic temperature. Constr Build Mater 189:1035-1044

11. Dave EV, Song SH, Buttlar WG, Paulino GH (2007) Reflective and thermal cracking modeling of aspha concrete overlays. Adv Charact Pavement Soil Eng Mater 2:1241-1252

12. Kim J, Buttlar WG (2002) Analysis of reflective crack control system involving reinforcing grid over base-isolating interlayer mixture. J Transp Eng 128(4):375-384

13. Lancaster IM, Khalid HA, Kougioumtzoglou IA (2013) Extended FEM modelling of crack propagation using the semi-circular bending test. Constr. Build Mater 48:270-277

14. Myers LA, Roque R, Birgison B (2001) Propagation mechanism for surface-initiated longitudinal wheel path cracks. Natl Res Counc 5(33):01-04

15. Huang $L$, Zhang $P$, Zhiqiang $H$ et al (2020) Fatigue expansion analysis of temperature shrinkage reflection cracks in semi-rigid base asphalt pavement. Highway Eng 45(5):79-83

16. Tran NP, Gunasekara C, Law DW, Houshyar S, Setunge S, Cwirzen A (2021) A critical review on drying shrinkage mitigation strategies in cement-based materials. J Build Eng 38:102210

17. Qomi MJA, Brochard L, Honorio T, Maruyama I, Vandamme M (2021) Advances in atomistic modeling and understanding of drying shrinkage in cementitious materials. Cem Concr Res 148:106536

18. Song Y, Wu Q, Agostini F, Skoczylas F, Bourbon X (2021) Concrete shrinkage and creep under drying/wetting cycles. Cem Concr Res 140:106308

19. Revilla-Cuesta V, Evangelista L, de Brito J, Ortega-López V, Manso JM (2021) Effect of the maturity of recycled aggregates on the 
mechanical properties and autogenous and drying shrinkage of high-performance concrete. Constr Build Mater 299:124001

20. Tong Z, Wang Z, Wang X, Ma Y, Guo H, Liu C (2021) Characterization of hydration and dry shrinkage behavior of cement emulsified asphalt composites using deep learning. Constr Build Mater 274:121898

21. Li W, Lang L, Lin Z et al (2017) Characteristics of dry shrinkage and temperature shrinkage of cement-stabilized steel slag. Constr Build Mater 134:540-548

22. Zhu Y, Liu Y, Cao W et al (2006) A fine-scale model analysis of moisture and dry shrinkage deformation and stress characteristics of concrete. J Water Resour 37(10):1163-1168

23. Zhang $X$ (2018) Calculation method of dry shrinkage stress of semi-rigid subgrade in construction hardening stage. Transp Sci Technol 290(05):48-50

24. Li L, Wang T (2005) Extended finite element method (XFEM) and its applications. Adv Mech 35(001):5-20

25. Yi S, Chen Q, Liu P et al (2021) Research on crack expansion based on extended finite element method. Sci Technol Innov 20:64-67

26. Bybordiani M, Latifaghili A, Soares D et al (2021) An XFEM multiayered Heaviside enrichment for fracture propagation with reduced enhanced degrees of freedom. Int J Numer Method Eng 14(122):3425-3447

27. Rong H, Wang J, Liu J (2013) Finite element analysis of reflection crack expansion in asphalt pavement. Low Temp Constr Technol 35(11):135-138
28. Yang Q (2019) Effect of microcracks on cracking of semi-rigid base asphalt pavement. Traffic World 21:66-67

29. Huang LK, Song W, Jiang ZH et al (2021) Effect of temperature and vehicle speed on modulus field and fatigue life of semi-rigid base asphalt pavement. J Hunan Univ (Nat Sci Ed) 48(05):148-156

30. Zhang M, Jiang Y, Guo C et al (2020) Analysis of mechanical response of asphalt pavement with different underseal layers under dynamic loading. J Shenyang Univ Archit (Nat Sci Ed) 184(01):106-114

31. Jia K, Sha AM, JianQing L (2009) Effective modulus values of semi-rigid base materials. J Chang'an Univ (Nat Sci Ed) 29(1):5

32. Gao JP, Cuiling P, Zhao YX et al (2010) Experimental study on the dry shrinkage performance of semi-rigid base materials containing sulfate. J Xi'an Univ Archit Technol (Nat Sci Ed) 42(3):6

33. Xuchun $H$, Rui Z, Feng R (2016) Numerical simulation analysis of crack extension based on ABAQUS platform. Mach Build 54(005):37-40

Publisher's Note Springer Nature remains neutral with regard to jurisdictional claims in published maps and institutional affiliations. 